\title{
FAKTOR FAKTOR YANG BERHUBUNGAN DENGAN KUALITAS HIDUP PADA CAREGIVER KLIEN SKIZOFRENIA
}

\author{
Helena Patricia ${ }^{1}$, Veolina Irman ${ }^{2}$ \\ ${ }^{1}$ Program Studi Sarjana Keperawatan \\ Stikes Syedza Saintika, Jl. Prof. Dr. Hamka No. 228 Air Tawar Timur, Padang, Indonesia \\ (helenapatricia77@gmail.com, 085265409500)
}

\begin{abstract}
ABSTRAK
Proses merawat klien skizofrenia menciptakan situasi yang penuh stress, ketidaksiapan caregiver dalam menghadapi masalah ini berdampak pada penurunan kualitas hidup. Penurunan kualitas hidup caregiver dipengaruhi oleh beberapa faktor diantaranya karakteristik caregiver yang meliputi usia, jenis kelamin, status marital, tingkat pendidikan, pekerjaan, penghasilan, dan hubungan caregiver dengan klien. Penelitian ini bertujuan untuk mengetahui hubungan karakteristik caregiver dengan kualitas hidup pada caregiver. Desain penelitian ini adalah deskriptif analitik dengan pendekatan cross sectional study pada 186 caregiver dengan convenient technique sampling. Data dikumpulkan dengan kuesioner World Health Organization Quality of Life (WHOQOL-BREF). Hasil penelitian menunjukkan sebagian besar responden perempuan $(62,9 \%)$, usia tahap dewasa pertengahan $(35,5 \%)$, menikah $(67,7 \%)$, pendidikan SMP (38.2\%), tidak bekerja $(67,2 \%)$, penghasilan dibawah UMR $(70,4 \%)$ dan merupakan orang tua dari klien skizofrenia (33,9\%), serta lebih dari setengah responden merasakan kualitas hidup yang rendah $(53,2 \%)$. Uji statistik chi-square membuktikan adanya hubungan signifikan antara usia $(0,033)$, jenis kelamin $(0,033)$, status marital $(0,000)$, tingkat pendidikan $(0,001)$, pekerjaan $(0,000)$, penghasilan $(0,002)$, dan hubungan caregiver dengan klien $(0,002)$ dengan kualitas hidup caregiver. Saran untuk Rumah Sakit Jiwa Tampan Pekanbaru untuk meningkatkan pelayanan keperawatan jiwa secara komprehensif terhadap klien dan keluarga, berupa program pendidikan kesehatan terutama untuk kelompok caregiver yang beresiko.
\end{abstract}

Kata Kunci : Kualitas hidup, karakteristik caregiver, skizofrenia

\begin{abstract}
Process of caring clients with schizophrenia impact stressful situations, caregiver unpreparedness in dealing with these issues impact on the quality of life. The decrease caregiver quality of life is influenced by several factors, including the caregiver characteristics that includes age, gender, marital status, education level, occupation, income, and caregiver relationships with clients. This study aims to determine the relationships between characteristics and quality of life among caregivers. Design of this research is descriptive analytic with cross sectional study on 186 caregiver with convenient technique sampling. Data were collected by The the World Health Organization Quality of Life (WHOQOL-BREF) questionnaire. The results showed most of caregiver are woman (62,9\%), middle aged adult $(35,5 \%)$, married (67,7\%), Junior high school (38.2\%), do not have a job (67,2\%), income below the minimum wage $(70,4 \%)$, parents of clients with schizophrenia $(33,9 \%)$, and more than half respondents feel low quality of life (53,2\%). Chi-square statistics shows the significant relationship between age (0.033), gender ( 0.033), marital status (0,000), education level (0,001), jobs (0,000), income (0,002), and the relationship between caregiver with clients ( 0,002) with the caregiver's quality of life. Suggestions for the Mental Hospital Tampan Pekanbaru to improve nursing services comprehensively for clients and family, such as health education programs.
\end{abstract}

Keywords: Quality of life, characteristic caregiver, schizophrenia 


\section{Latar Belakang}

Skizofrenia adalah kombinasi dari gangguan pikir, persepsi, perilaku, gangguan afektif dan ketidakmampuan dalam bersosialisasi (Fontaine, 2009). Diperkirakan 450 juta orang di dunia mengalami skizofrenia (World Health Organization 2009). Prevalensi skizofrenia di Indonesia menurut Riskesdas tahun 2013 mencapai 1,7 per 1.000 populasi penduduk, dan di Riau sebanyak 0,9 per 1.000 populasi penduduk.

Klien skizofrenia menunjukkan durasi penyakit yang panjang, gejala terus menerus, sering kambuh dan menyebabkan ketidakmampuan. Oleh karena itu klien membutuhkan seorang caregiver. Sebagian besar klien skizofrenia dirawat di masyarakat oleh caregiver.

Caregiver adalah seseorang baik keluarga, teman, atau hubungan lain yang memberi perawatan dan dukungan fisik, praktis dan emosional kepada klien (Lubkin, I.M dan Larsen, P.O, 2006). Studi menunjukkan bahwa di negara Barat, sekitar 25\%-50\% klien skizofrenia tinggal dengan caregiver. Di Asia 70\% klien skizofrenia dirawat caregiver (Chan \& $\mathrm{Yu}$, 2004).

Caregiver yang merawat klien skizofrenia mempunyai stress psikologis yang kuat dan rasa khawatir dalam merawat klien. Masalah yang dihadapi yaitu masalah emosional, masalah finansial, dan masalah kesehatan fisik (Psychiatrist's perspectives on mental illness and wellness, 2006). Ketidaksiapan caregiver menghadapi masalah berdampak pada kesehatan mental dan penurunan kualitas hidup (Lam, P., Ng, P., \& Tori, C, 2013).

Kualitas hidup adalah persepsi individu terhadap posisi mereka dalam kehidupan dalam konteks budaya dan nilai dimana mereka hidup dan dalam hubungannya dengan tujuan hidup, harapan, standard dan perhatian (World Health Organization, 2004). Pengukuran kualitas hidup bersifat multidimensi, meliputi dimensi kesehatan fisik, psikologis, hubungan sosial, dan hubungan dengan lingkungan.

Penurunan kualitas hidup pada caregiver klien skizofrenia dipengaruhi oleh beberapa faktor, faktor yang paling dominan adalah karakteristik caregiver (Caqueo, U., et al, 2009). Zarit, et al (1985 dalam Chou, et al 2009)

Hasil penelitian Chan (2004), menyatakan bahwa kualitas hidup caregiver klien skizofrenia berhubungan secara signifikan dengan jenis kelamin perempuan, caregiver yang tidak memiliki pekerjaan, dan lama klien skizofrenia menderita penyakit. 
Rumah Sakit Jiwa Tampan Pekanbaru merupakan pusat rujukan klien gangguan jiwa dan pusat pengembangan Keperawatan Jiwa di provinsi Riau. Berdasarkan data Rekam Medik, skizofrenia menempati urutan pertama diagnosa medis klien. Angka kunjungan Instalasi Rawat Jalan terus meningkat dan lebih banyak daripada rawat inap. Hal ini membuktikan banyaknya klien skizofrenia yang dirawat oleh keluarga di masyarakat.

Tujuan umum penelitian ini adalah untuk mengetahui hubungan karakteristik caregiver dengan kualitas hidup pada caregiver klien skizofrenia di Instalasi Rawat Jalan Rumah Sakit Jiwa Tampan Pekanbaru.

\section{Metode Penelitian}

Penelitian ini mengggunakan desain descriptive analytic dengan pendekatan cross sectional study. Dilakukan pada 186 caregiver di Instalasi Rawat Jalan Rumah Sakit Jiwa Tampan Pekanbaru pada bulan Juni - Juli 2015, dengan kriteria inklusi: family caregiver berusia 18-65 tahun, merawat klien dengan diagnosa medis skizofrenia yang sudah dapat berfungsi secara stabil dalam masyarakat, minimal sudah merawat klien selama 6 bulan, mampu membaca dan menulis serta menyetujui untuk menjadi responden.

Kualitas hidup dikaji dengan kuesioner World Health Organization Quality of Life
(WHOQOL-BREF) oleh Skevington et al (2004). Kuesiner ini telah dilakukan uji validitas dan reliabilitas dan dinyatakan telah valid dan reliabel. Data karakteristik responden meliputi usia, jenis kelamin, status marital, pendidikan, penghasilan, dan hubungan dengan klien.

Penelitian ini memperhatikan prinsip dasar etik penelitian yang meliputi autonomy, beneficence, maleficence, anonimity dan justice (Polit \& Back, 2008). Analisa data yang digunakan adalah univariat, bivariat, dan. Univariat melihat distribusi frekuensi, kualitas hidup, dan karakteristik caregiver. Bivariat dengan chi-square mengkaji hubungan antara karakteristik dengan kualitas hidup.

\section{Hasil Penelitian}

Hasil penelitian pada 186 orang caregiver klien skizofrenia menunjukkan bahwa sebagian besar adalah responden perempuan $(62,9 \%)$, usia tahap dewasa pertengahan $(35,5 \%)$, menikah $(67,7 \%)$, pendidikan SMP (38.2\%), tidak bekerja $(67,2 \%)$ penghasilan dibawah UMR $(70,4 \%)$ dan merupakan orang tua dari klien skizofrenia $(33,9 \%)$ (Tabel 1).

Tabel 2 menjelaskan tentang distribusi frekuensi kualitas hidup caregiver. Hasil menunjukkan bahwa lebih dari setengah responden mengungkapkan merasakan 
kualitas hidup yang rendah, yaitu sebanyak 99 orang $(53,2 \%)$ responden.

\section{Tabel 1}

Distribusi frekuensi karakteristik caregiver klien skizofrenia $(\mathrm{N}=186)$

\begin{tabular}{|c|c|c|c|}
\hline Variabel & Kategori & Jumlah & Persentase \\
\hline \multirow[t]{3}{*}{ Usia } & $\begin{array}{l}\text { Dewasa } \\
\text { awal }\end{array}$ & 65 & 34,9 \\
\hline & $\begin{array}{l}\text { Dewasa } \\
\text { pertengahan }\end{array}$ & 66 & 35,5 \\
\hline & $\begin{array}{l}\text { Dewasa } \\
\text { akhir }\end{array}$ & 55 & 29,6 \\
\hline \multirow{2}{*}{$\begin{array}{l}\text { Jenis } \\
\text { kelamin }\end{array}$} & Laki-laki & 69 & 37,1 \\
\hline & Perempuan & 117 & 62,9 \\
\hline \multirow{2}{*}{$\begin{array}{l}\text { Status } \\
\text { marital }\end{array}$} & Menikah & 126 & 67,7 \\
\hline & $\begin{array}{l}\text { Tidak } \\
\text { menikah }\end{array}$ & 60 & 32,3 \\
\hline \multirow{4}{*}{$\begin{array}{l}\text { Tingkat } \\
\text { pendidikan }\end{array}$} & SD & 38 & 20,4 \\
\hline & SMP & 71 & 38,2 \\
\hline & SMA & 53 & 28,5 \\
\hline & $\begin{array}{l}\text { Perguruan } \\
\text { tinggi }\end{array}$ & 24 & 12,9 \\
\hline \multirow[t]{3}{*}{ Pekerjaan } & Bekerja & 61 & 32,8 \\
\hline & Tidak & & \\
\hline & bekerja & 125 & 67,2 \\
\hline \multirow[t]{2}{*}{ Penghasilan } & $\begin{array}{l}\text { Dibawah } \\
\text { UMR }\end{array}$ & 131 & 70,4 \\
\hline & $\begin{array}{l}\text { Diatas } \\
\text { UMR }\end{array}$ & 55 & 29,6 \\
\hline \multirow{4}{*}{$\begin{array}{l}\text { Hubungan } \\
\text { Caregiver- } \\
\text { klien }\end{array}$} & Pasangan & 39 & 21,0 \\
\hline & Orang tua & 63 & 33,9 \\
\hline & Anak & 54 & 29,0 \\
\hline & Saudara & 30 & 16,1 \\
\hline
\end{tabular}

\section{Tabel 2}

Distribusi frekuensi kualitas hidup caregiver klien skizofrenia $(\mathrm{N}=186)$

\begin{tabular}{lccc}
\hline \multicolumn{1}{c}{ Variabel } & Kategori & Jumlah & Persentase \\
\hline $\begin{array}{l}\text { Kualitas } \\
\text { Hidup }\end{array}$ & Rendah & 99 & 53,2 \\
& Tinggi & 87 & 46,8 \\
\hline
\end{tabular}

Tabel 3 menunjukkan bahwa terdapat hubungan antara semua karakteristik caregiver (usia, jenis kelamin, status marital, tingkat pendidikan, pekerjaan, penghasilan, dan hubungan caregiver dengan klien) dengan kualitas hidup, dimana ditemukan nilai $\mathrm{p}$ value $<0,05$ pada derajat kepercayaan 5\% pada semua varibel.

\section{Tabel 3}

Hubungan karakteristik caregiver dengan kualitas hidup caregiver $(\mathrm{N}=186)$

\begin{tabular}{|c|c|c|c|c|c|c|c|}
\hline \multirow{3}{*}{$\begin{array}{l}\text { Karakteristik } \\
\text { Responden }\end{array}$} & \multicolumn{4}{|c|}{$\begin{array}{c}\text { Kualitas Hidup } \\
\text { Caregiver }\end{array}$} & \multirow{2}{*}{\multicolumn{2}{|c|}{ Total }} & \multirow[t]{2}{*}{$\mathrm{P}$} \\
\hline & \multicolumn{2}{|c|}{ Rendah } & \multicolumn{2}{|c|}{ Tinggi } & & & \\
\hline & $\mathrm{f}$ & $\%$ & $\mathrm{~F}$ & $\%$ & $\mathrm{f}$ & $\%$ & \\
\hline \multicolumn{8}{|l|}{ Usia } \\
\hline Dewasa awal & 33 & 50,8 & 32 & 49,2 & 65 & 100 & \multirow{4}{*}{$\begin{array}{c}0,03 \\
3\end{array}$} \\
\hline Dewasa tengah & 29 & 43,9 & 37 & 56,1 & 66 & 100 & \\
\hline Dewasa akhir & 37 & 67,3 & 18 & 32,7 & 55 & 100 & \\
\hline Total & 99 & 53,2 & 87 & 46,8 & 186 & 100 & \\
\hline \multicolumn{8}{|l|}{ Jenis Kelamin } \\
\hline Wanita & 55 & 62,3 & 62 & 53,0 & 117 & 100 & \multirow{3}{*}{$\begin{array}{c}0,03 \\
3\end{array}$} \\
\hline Pria & 44 & 63,8 & 25 & 36,2 & 69 & 100 & \\
\hline Total & 99 & 53,2 & 87 & 46,8 & 186 & 100 & \\
\hline \multicolumn{8}{|l|}{ Status Marital } \\
\hline Menikah & 45 & 35,7 & 81 & 64,3 & 60 & 100 & \multirow{3}{*}{$\begin{array}{c}0,00 \\
0 \\
\end{array}$} \\
\hline Tidak menikah & 54 & 90,0 & 6 & 10,0 & 126 & 100 & \\
\hline Total & 99 & 53,2 & 87 & 46,8 & 186 & 100 & \\
\hline \multicolumn{8}{|l|}{ Pendidikan } \\
\hline SD & 22 & 57,9 & 61 & 42,1 & 38 & 100 & \multirow{5}{*}{$\begin{array}{c}0,00 \\
1\end{array}$} \\
\hline SMP & 49 & 69,0 & 22 & 31,0 & 71 & 100 & \\
\hline SMA & 18 & 34,0 & 35 & 66,0 & 53 & 100 & \\
\hline PT & 10 & 41,7 & 14 & 58,3 & 24 & 100 & \\
\hline Total & 99 & 53,2 & 87 & 46,8 & 186 & 100 & \\
\hline \multicolumn{8}{|l|}{ Status Bekerja } \\
\hline Bekerja & 15 & 24,6 & 46 & 75,4 & 61 & 100 & \multirow{3}{*}{$\begin{array}{c}0,00 \\
0\end{array}$} \\
\hline Tidak bekerja & 64 & 67,2 & 41 & 32,8 & 125 & 100 & \\
\hline Total & 99 & 53,2 & 87 & 46,8 & 186 & 100 & \\
\hline \multicolumn{8}{|l|}{ Penghasilan } \\
\hline Dibawah UMR & 80 & 61,1 & 51 & 38,9 & 131 & 100 & \multirow{3}{*}{$\begin{array}{c}0,00 \\
2\end{array}$} \\
\hline Diatas UMR & 19 & 34,5 & 36 & 65,5 & 55 & 100 & \\
\hline Total & 99 & 53,2 & 87 & 46,8 & 186 & 100 & \\
\hline \multicolumn{8}{|l|}{ Hubungan } \\
\hline Pasangan & 14 & 35,9 & 25 & 64,1 & 39 & 100 & \multirow{5}{*}{$\begin{array}{c}0,00 \\
2\end{array}$} \\
\hline Anak & 28 & 44,4 & 35 & 55,6 & 63 & 100 & \\
\hline Orangtua & 39 & 72,2 & 15 & 27,8 & 54 & 100 & \\
\hline Saudara & 18 & 60,0 & 12 & 40,0 & 30 & 100 & \\
\hline Total & 99 & 53,2 & 87 & 46,8 & 186 & 100 & \\
\hline
\end{tabular}

\section{Pembahasan}

Proses merawat klien skizofrenia mendatangkan masalah pada caregiver. Masalah tersebut lebih dikenal sebagai beban caregiver. Caregiver merasakan masalah secara terus menerus dalam jangka 
waktu yang lama akan berdampak pada kesehatan fisik yang menurun, peningkatan gejala stress psikologis, merasakan stigma yang negatif, terbatasnya waktu untuk bersosialisasi. Dampak tersebut merupakan bagian dari domain kualitas hidup, sehingga disimpulkan caregiver yang mengalami beban berat akan merasakan dampaknya terhadap kualitas hidup (Kaushik, P \& Bhatia, M.S, 2013).

White, et al., (2004) mengungkapkan terdapat tiga faktor yang mempengaruhi kualitas hidup caregiver, yaitu situasi merawat klien yang mencakup beban perawatan, faktor caregiver meliputi karakteristik, dan faktor lingkungan mencakup dukungan keluarga. Penurunan kualitas hidup caregiver pada klien skizofrenia dipengaruhi oleh faktor kondisi caregiver, kurangnya dukungan sosial, perjalanan penyakit memanjang dan masalah hubungan keluarga (Caqueo, $\mathrm{U}$ et al, 2009).

Hasil analisis hubungan antara karakteristik responden dengan kualitas hidup caregiver diperoleh bahwa semua karakteristik responden memiliki hubungan signifikan dengan beban caregiver. Analisis lebih lanjut pada alpha 5\% terdapat hubungan signifikan antara usia $(\mathrm{p}=0,033)$, jenis kelamin $(\mathrm{p}=0,033)$, status marital $(\mathrm{p}=0,000)$, pendidikan $(\mathrm{p}=0,001)$, status bekerja $(\mathrm{p}=0,001)$, penghasilan $(\mathrm{p}=0,002)$, dan hubungan caregiver-klien $(\mathrm{p}=0,002)$ dengan kualitas hidup caregiver.

Kualitas hidup caregiver klien skizofrenia ditemukan berhubungan dengan faktor psikososial caregiver, caregiver yang berusia lebih tua, caregiver wanita, dengan status sosial ekonomi yang lebih rendah, ditemukan berhubungan dengan rendahnya kualitas hidup (Zamzam, et al, 2011). Chan (2004), menyatakan bahwa kualitas hidup caregiver klien skizofrenia berhubungan dengan jenis kelamin perempuan, tidak memiliki pekerjaan, dan lama klien menderita penyakit.

Hasil Penelitian Chan et al (2005), menyatakan bahwa laki-laki dan perempuan yang sudah menikah dan memiliki pasangan mempunyai kualitas hidup yang lebih tinggi, hal ini dipengaruhi karena adanya dukungan sosial dari pasangan. Juvang, L., Lambert C. E., \& Lambert, V. A. (2007), dalam penelitiannya juga mengatakan bahwa kualitas hidup berhubungan secara signifikan dengan tingkat pendidikan caregiver, dimana kualitas hidup cendrung lebih tinggi pada caregiver yang memiliki pendidikan tinggi.

Caregiver berpendidikan lebih rendah, cendrung memiliki pekerjaan yang kurang baik, akan mempunyai gaji yang rendah, memiliki kekurangan sumber daya finansial dan sosial, sehingga akan menghasilkan kualitas hidup yang lebih rendah (Wong, D., Lam, A., Chan S., \& Chan, F., 2012). 
Awadalla, et al pada tahun 2005 yang menunjukkan bahwa orang tua dari klien dengan penyakit mental memiliki kualitas hidup yang lebih rendah dibandingkan dengan kategori hubungan lainnya. Gutiérrez, M. J., Caqueo, U. A., \& Kavanagh, D. J., (2005), juga menyatakan bahwa status kekerabatan antara caregiver klien skizofrenia diidentifikasi sebagai prediktor signifikan dari beban subjektif caregiver yang terkait dengan kualitas hidupnya.

\section{Kesimpulan}

Karakteristik caregiver sebagian besar berjenis kelamin perempuan, dengan usia berada pada tahap dewasa pertengahan, dengan status marital menikah, tingkat pendidikan terbanyak adalah SMP, tidak bekerja, dengan penghasilan dibawah UMR dan merupakan orang tua dari klien skizofrenia. Lebih dari separuh caregiver mengungkapkan merasakan kualitas hidup yang rendah. Terdapat hubungan yang signifikan antara semua karakteristik caregiver dengan kualitas hidup pada caregiver klien skizofrenia.

\section{Saran}

Saran Bagi Rumah Sakit Jiwa Tampan Pekanbaru untuk meningkatkan pelayanan keperawatan jiwa, terutama intervensi untuk keluarga klien serta pelaksanaan terapi spesialis untuk keluarga seperti Family Psychoeducation Therapy (FPE) untuk membantu keluarga mengatasi masalah beban berat selama perawatan serta membuat kelompok pendukung bagi keluarga. Bagi Institusi Pendidikan Ilmu Keperawatan diharapkan mampu memanfaatkan hasil penelitian untuk pengembangan ilmu tentang beban dan kualitas hidup. Serta adanya penelitian lanjutan dengan desain yang lebih bisa mengkuantifikasi secara tepat beban caregiver dan kualitas hidup.

\section{Daftar Pustaka}

Awadalla, A.W., Ohaeri, J.U., Salih, A. A., \& Tawfiq, A. M. (2005). Subjective quality of life of family caregivers of community living Sudanese psychiatric patients. Soc Psychiatry Psychiatr Epidemiol. 40(9):755-63.

Caqueo, U., et al. (2009). Quality of life in caregivers of patients with schizophrenia: A literature review. Health and Quality of Life Outcomes 2009, 7:84.

Chan, S., Yip, B., Tso, S., Cheng, B.S., \& Tam, W. (2009). Evaluation of a sychoeducation program for Chinese clients with schizophrenia and their family caregivers. Patient Education and Counseling, 75, 6776. 2.219.

Chan, S., \& Yu, I. W. (2004). The quality of life of clients with schizophrenia. Journal of Advanced Nursing, 45(1), 72-83. 
Chou, K. R. (2000). Caregiver burden: A concept analysis. Journal of Pediatric Nursing, 15, 398-399.

Fontaine, K.L. (2009). Mental Health Nursing. New Jersey. Pearson Education. Inc

Gutiérrez, M. J., Caqueo, U. A., \& Kavanagh, D. J. (2005). Burden of care and general health in families of patients with schizophrenia. Social Psychiatry And Psychiatric Epidemiology, 40(11), 899-904.

Juvang, L., Lambert C. E., \& Lambert, V. A. (2007). Predictors of family caregiveres burden and quality of life when providing care for a family member with schizophrenia in the people ${ }^{\text {es }}$ republic of China. Nursing and Health Sciences, 9, 192-198.

Kate, et al. (2013). Relationship of caregiver burden with coping strategies, social support, psychological morbidity, and quality of life in the caregivers of schizophrenia. Asian Journal Psychiatry 2013 Oct;6(5):380-8.

Kaushik, P \& Bhatia, M.S. (2013). Burden and Quality of Life in Spouses of Patients with Schizophrenia and Bipolar Disorder. Delhi Psychiatry Journal 2013; 16: (1)

Lam, P., Ng, P., \& Tori, C. (2013). Burdens and Psychological Health of Family Caregivers of People with Schizophrenia in Two Chinese Metropolitan Cities: Hong Kong and Guangzhou. Community Ment Health J 49:841-846

Lubkin, I.M \& Larsen, P.O. (2006). Chronic illness: impact and intervention. Jones and Barlett
Publisher, Inc Sudbuy Messachusetts.

Magaña, S. M., Ramírez, G. J. I., Hernández, M. G., \& Cortez, R. (2007). Psychological distress among Latino family caregivers of adults with schizophrenia: The roles of burden and stigma. Psychiatric Services, 58(3), 378-384.

Ohaeri, J. U. (2001). Caregiver burden and pshycotic patient's perception of social support in a Nigerian setting. Soc pschyatric epidemiol (2001) 36:86-93

Psychiatrist's perspectives on mental illness and wellness. (2006). The Caregiver perspective: Caregivers of Individuals with Bipolar Disorder, Schizophrenia and Schizoaffective Disorder. Diperoleh pada tanggal 1 April 2015 dari www.wfmh.com/ WFMH_GIAS_Caregiver_FactShee

Rafiyah, W., Suttharangsee and H. Sangchan, (2011). Burden on Family Caregivers Caring for Patients with Schizophrenia. Nurse Media Journal of Nursing, 1, 1, January 2011, $29-41$

White, et al. (2004). Toward a model of quality of life for family caregivers of stroke survivors. Quality of Life Research. 13:625-638.

Winahyu, K., M. (2014). Perceived Control of Symptoms, Caregiver Burden, Perceived Social Support and Quality of Life among Family Caregivers of Patients with Schizophrenia in Indonesia. $J$ Prapokklao Hosp Clin Med Educat Center, 32:44-57

Wong, D., Lam, A., Chan, S., \& Chan, F. (2012). Quality of life of caregivers 
with relatives suffering from mental illness in Hongkong: roles of caregiver characteristics, caregiving burdens, and satisfaction with psychiatric services. Health and Quality of Life Outcomes, 10: 1-9.

World Federation of Mental Health. (2010). Caring for the caregiver: Why your mental health matters when you are caring for others. Diperoleh dari www.Woodbridge.VA:WFMH pada tanggal 12 April 2015

Word Federation For Mental health (2008). Leraning about Schizophrenia: An international Mental Health Awareness Packet. Diperoleh dari http:///www.wfmh.org.pada tanggal 28 Maret 2015

World Health Organization (2010). Schizophrenia. Diperoleh pada tanggal 25 maret 2015 dari http://www.who.int/

World Health Organization (2009). Investing in Mental Health. Diperoleh pada tanggal 25 maret 2015 dari $w w w . w h o . i n t / m e n t a l$

World Health Organization. (2004). Introducing the WHOQOL Instruments. Diperoleh dari http://dept. washington. edi/ yqol/docs/ whoqol_infopdf pada tanggal 1 April 2015

Zamzam, R., et al. (2011). Schizophrenia in Malaysian families: A study on factors associated with quality of life of primary family caregivers. International Journal of Mental Health Systems, 5(1), 16-18 